\title{
SATISFAÇÃO E MOTIVAÇÃO DOS FUNCIONÁRIOS NO IFRN - CAMPUS NATAL CENTRAL
}

\author{
I. C. S. ALMEIDA* e M. F. F. S. TACCONI \\ Instituto Federal do Rio Grande do Norte - IFRN \\ marli.tacconi@ifrn.edu.br ${ }^{*}$
}

Artigo submetido em agosto/2014 e aceito em junho/2015

DOI: 10.15628/holos.2015.2292

\section{RESUMO}

O objetivo deste trabalho é identificar os aspectos da satisfação e motivação dos funcionários técnicos administrativos do IFRN Campus Natal Central. Pois se considerando a importância social do setor público no país, deve-se promover estudos que visem avaliar os aspectos motivacionais que reforcem a satisfação do funcionário, visto que a qualidade no atendimento ao público externo tende a estar ligado à satisfação desse público para com a organização. Dessa forma, foi realizado um estudo de caráter exploratório e descritivo, do tipo estudo de caso e abordagem quantitativa. A população desta pesquisa foi formada pelos servidores técnico-administrativos do IFRN Campus Natal-Central, no qual se coletaram 136 questionários, atendendo ao critério de amostra probabilística. Os resultados apresentaram que as pessoas se sentem fortemente motivadas, evidenciando que a maioria deve gostar do trabalho que desenvolve. Esse mesmo resultado se confirma no nível de satisfação com o trabalho. Isso demostra que a maioria dos servidores trabalham com o que gostam, promovendo uma forte relação e sentindose satisfeitos como o seu trabalho. A análise de Cluster demonstrou que pode ser possível diferenciar dois agrupamentos, que apresentam nível de satisfação e motivação diferenciados. Conclui-se que os funcionários menos motivados são os que possuem mais tempo de serviço e que percebem o seu trabalho com menor nível de importância. Essa informação sugere uma urgência em destacar a importância do sentido do trabalho para esses profissionais.

PALAVRAS-CHAVE: Satisfação, motivação, endomarketing, cluster.

\section{SATISFACTION AND MOTIVATION OF EMPLOYEES OF THE IFRN - CAMPUS NATAL CENTRAL}

\begin{abstract}
The objective of this work is to identify the aspects of satisfaction and motivation of technical administrative of the IFRN Campus Natal Central. Because considering the social importance of the public sector in the country, should promote studies that aim to assess the motivational aspects that enhance employee satisfaction, since the quality of care to the general public tends to be linked to satisfaction this public to the organization. Thus, a study of exploratory and descriptive, quantitative and case study approach was conducted. The population of this research was formed by technical and administrative of the IFRN Campus Natal Central, in which 136 questionnaires were collected, given the criterion of probability sample. The results
\end{abstract}

showed that people feel strongly motivated, showing that most should enjoy the work that develops. This same result is confirmed in the level of job satisfaction. This demonstrates that most servers work with what they like, fostering a strong relationship and feeling satisfied as their job. The Cluster analysis showed that it may be possible to differentiate the two groupings, which have different levels of satisfaction and motivation. We conclude that employees are less motivated to have more years of service and who perceive their work with lower level of importance. This information suggests an urgency to highlight the importance of the meaning of work for these professionals

KEYWORDS: Satisfaction, motivation, endomarketing, cluster. 


\section{INTRODUÇÃO}

Para que um país se desenvolva de todas as formas, tem que se investir em educação, que é um dos fatores mais importante para o desenvolvimento de uma nação. É através do conhecimento que um país cresce. (SOUSA, 1984). Para um país ter evolução, é preciso investir em uma educação de qualidade tanto na escola (Ensino Fundamental e Médio), quanto na universidade. No entanto, a população tem culpado o poder público pela má qualidade na educação, mas vale ressaltar que para um funcionário da área educacional estar motivado a fazer um bom trabalho, não precisa apenas receber um bom salário. O reconhecimento profissional e o respeito por parte da população são fatores que influenciam fortemente no comportamento desses profissionais dentro de uma instituição.

O setor público educacional do nosso país apresentam carências, desmotivando muitos profissionais da área a exercer de maneira eficiente o seu serviço. A motivação e a satisfação dos funcionários são aspectos importantes para que eles possam oferecer um atendimento interno e externo de qualidade, fortalecendo assim o marketing institucional. A falta desses aspectos nos servidores públicos é um dos principais problemas que mais afligem os usuários e que geram reclamações dos que precisam buscar esses serviços. Diante desta problemática que se buscam as questões relevantes da falta de motivação e satisfação destes servidores.

Ao longo da história do IFRN constata-se a necessidade da preparação de nossos jovens, de uma maneira promissora, a fim de que se possam incluí-los na sociedade com uma participação ativa no processo social. Este processo torna-se uma das metas da escola pública, por isso a organização dos conhecimentos é proposta pela instituição visando à ampliação das competências intelectuais dos alunos.

Nenhum programa ou ação voltada para o cliente externo funcionam sem uma profunda atenção e investimento no marketing interno. A questão da remuneração não é o único incentivo para satisfazer o funcionário, pois o mesmo precisa ser estimulado por incentivos psicológicos e sociais, por exemplo, o funcionário precisa de estímulos, como o reconhecimento e o elogio que podem torná-los mais satisfeitos e motivados, na maioria das vezes, podem ser sinônimos de um melhor e mais eficiente rendimento profissional. Diante disso, surgiu o interesse em responder a seguinte questão: Qual o nível de satisfação e motivação dos servidores técnicos administrativos com o trabalho que desenvolvem no IFRN Campus Natal Central?

Nessa perspectiva, o objetivo deste trabalho é identificar os aspectos da satisfação e motivação dos funcionários técnico administrativos do IFRN Campus Natal Central. E de forma específica, identificar o nível de satisfação dos técnicos administrativo do IFRN Campus Natal Central; e verificar o nível de motivação dos técnicos administrativos no atendimento prestado pelos mesmos aos seus usuários.

Esses objetivos tem o intuito de identificar possíveis ações para promover o endomarketing, endomarketing é um processo que envolve troca de informações com o público interno, melhorando a satisfação e a motivação dos funcionários, que irão se refletir em um melhor atendimento ao cidadão usuário do IFRN. 


\section{REFERENCIAL TEÓRICO}

A satisfação e a motivação dos funcionários públicos é um dos fatores que mais influenciam na qualidade e no atendimento ao público externo. Nesse caso, o público são os usuários de uma instituição de ensino no qual foi desenvolvido um estudo para avaliar o quanto os funcionários administrativos estão satisfeito e motivado com as suas funções.

A perspectiva sobre o nível de qualidade do serviço oferecido aos usuários foi o fio condutor que gerou uma pesquisa usando o endomarketing, que é um processo que envolve troca de informações com o público interno, melhorando a satisfação e a motivação dos funcionários, consecutivamente esses profissionais satisfeitos e motivados demostram e oferecem melhores serviços, podendo se refletir em um público alvo mais satisfeito.

\subsection{A GESTÃO PÚBLICA}

As instituições públicas vêm passando por reformulação ao longo dos anos em sintonia com as profundas mudanças do mercado, bem como com as novas exigências da sociedade. Isto acontece porque a organização pública, como toda organização, é um sistema social aberto que está em permanente interação com o meio ambiente, influenciando-o e sendo por ele influenciada (CARVALHO; NASCIMENTO, 2004).

Segundo Corrêa e Freitas (1999), o papel social da organização pública é a prestação de serviços com qualidade, zelo, cuidado e responsabilidade pelo atendimento ao público e a economia de seus recursos sem esquecer seus princípios fundamentais como a legalidade, impessoalidade, moralidade, publicidade e eficiência.

Nesse sentido, o novo modelo gerencial do Estado busca ferramentas até então só encontradas nas empresas privadas com o objetivo de revitalização e agilização das suas organizações públicas. Assim, para cumprir o seu papel social e enfrentar os desafios e problemas organizacionais, a organização pública se assemelha com a organização privada, na medida em que necessita aplicar processos administrativos comuns ao gerenciamento como planejamento, organização, direção e controle.

Por outro lado, segundo Kliksberg (1993), gerenciar organizações públicas é bem diferente de gerenciar organizações privadas, seja quanto às suas opções, aos problemas de compatibilização dos objetivos e aos problemas de restrições e proibições. Percebe-se que, enquanto o executivo de negócios pode usualmente redefinir as metas da organização, modificar sua estrutura e mudar seu pessoal; o gestor público deve ter habilidades que lhe permitam operar dentro de metas e com recursos fixados por lei, de estruturas organizacionais rígidas e com funcionários controlados e protegidos pelo sistema jurídico, além da constante interferência política.

Outro fator, é que a organização pública, diferentemente da privada, tem por finalidade atender aos mais variados interesses da coletividade, essenciais à ordem social e econômica. Assim, ela destina seus objetivos e ações ao cliente-cidadão, que manifesta suas necessidades e escolhas por ser detentor de direitos e deveres recomendado na constituição. 


\subsection{SATISFAÇÃO E MOTIVAÇÃO}

Levando em conta a importância social do setor público no país, devem-se promover estudos que visem avaliar os aspectos motivacionais que reforcem a satisfação do funcionário (público interno), visto que a qualidade no atendimento ao público externo tende a estar ligado à satisfação desse público para com a organização.

De acordo com Robbins (2009), os fatores que determinam a satisfação no trabalho são: trabalho mentalmente desafiador, recompensas, justas, condições de trabalho, bons colegas de trabalhos que ajudem e os apoiem em todos os sentidos.

De acordo com o autor acima, a satisfação do funcionário com o seu trabalho, tende a ser mais forte quando ele fala bem da organização, ajudar seus colegas, e ultrapassar as expectativas em relação ao trabalho. Além disso, funcionários satisfeitos trabalham com mais disposição, contribuindo com a melhoria do ambiente de trabalho.

A motivação, comprometimento e alinhamento com os objetivos organizacionais são atributos desejados em todas as organizações. Conhecer seus empregados, seus anseios e o que os levam a se tornar motivados e a se comprometerem inquietam muitos líderes e gestores, especialmente os profissionais da área de Gestão de Pessoas. Cada vez mais as organizações se voltam às questões de motivação de seus empregados, pois a eficácia e o desempenho positivo estão diretamente ligados à motivação.

Segundo Weisinger (2001), um empregado motivado requer menos controle, tem uma produtividade consistente e tende a ser mais esforçado e criativo. Para Mendes $(2004$, p. 5) a motivação é importante para o alinhamento e o comprometimento dos funcionários. Então, como conseguir empregados motivados? Para que a organização tenha empregados motivados ela precisa ter uma visão de negócio. O compromisso só acontece quando o empregado compartilha dessa visão e o crescimento da empresa significa o seu próprio crescimento. E o instrumento para que isso aconteça é o Endomarketing. "Apoiado na comunicação, Endomarketing é um processo que envolve troca de informações ou informação com o público interno".

\subsection{MARKETING DE SERVIÇOS}

Uma das áreas importantes para a realização dessa pesquisa é o marketing de serviços, uma vez que o IFRN se trata de um ambiente no qual a sua principal função é prestar serviços de educação tecnológica e profissional para a sociedade.

O serviço por ser intangível, não possui as mesmas características de um produto, mesmo que esteja ligado a este último, uma vez que não pode ser armazenado, refeito ou trocado. Qualquer ação sobre um determinado serviço que não foi prestado da forma esperada constitui em si um novo serviço, diferentemente de um produto que pode ser consertado. (LOVELOCK; WRIGHT 2001).

De acordo com Cobra (2009), o desempenho do cliente interno e essencial para que o planejamento de marketing seja positivo. Porque os funcionários insatisfeitos tendem a atender mal. E o grau de insatisfação dos funcionários é perceptível observando-se a maneira com que o serviço está sendo oferecido. Esse processo gera clientes também insatisfeitos, como em uma espiral negativa. 
Cobra (2004), enfatiza que qualquer serviço é um compromisso com o cliente, seja em um hospital, banco, hotel ou companhia áreas o risco de mau atendimento está evidente, mas seu efeito pode variar dependendo do tipo de serviço, alguns podem ter consequências bem maiores, chegando até a mortes de pessoas ou grupos.

A comunicação e o marketing interno estão diretamente ligados com a gestão de pessoas na empresa, que de acordo com Brum (2010), não é fácil de administrar a relação capital e trabalho. O rancor pode se tornar vigente na empresa porque o empregado sente raiva dessa relação patrão/empregado, que é proveniente de uma economia instável.

Brum (2010) reforça que as empresas desejam mais que motivação, elas querem o engajamento dos colaboradores que é adquirido através da informação. A empresa pode estimular as pessoas trabalhando dois aspectos que são: a informação e a integração. Para isso, a organização tem que desenvolver primeiro um bom aspecto de informação para depois realizarem ações de integração no ambiente de trabalho.

\section{METODOLOGIA}

Foi realizado um estudo de caráter exploratório e descritivo, no qual buscou explorar novos conhecimentos sobre dados referentes à satisfação e motivação dos técnicos administrativos do IFRN Campus Natal Central, e descrever informações relevantes das análises desenvolvidas.

Está pesquisa trata de um estudo de caso com abordagem quantitativa. Quanto à técnica de estudo, foi realizado um levantamento. Segundo Gil (2010), o levantamento envolve a interrogação direta de pessoas cujo comportamento se deseja conhecerem, através da solicitação de informações a um grupo significativo de pessoas, acerca da problemática estudada, procura-se interpretar os dados coletados, mediante análises das respostas por meio de tabulação, para em seguida, obter as conclusões correspondentes a estes dados.

$\mathrm{Na}$ execução deste trabalho, foram utilizadas fontes primárias na coleta de informações com a satisfação e motivação dos técnicos administrativos do IFRN Campus Natal Central, como também, fontes secundárias através de livros e artigos.

Quanto ao instrumento, foi utilizado um questionário estruturado, com questões fechadas, ou seja, com perguntas que apresentam categorias ou alternativas de respostas fixas e preestabelecidas. Foi utilizada para tal propósito a escala Likert (escala de 5 pontos). De acordo com Malhotra (2006), Likert e uma escala de mensuração de cinco categorias de respostas variando de discordo totalmente até concordo totalmente, que exigem que o participante indique uma grade de concordância para cada uma das concordâncias ou de discordância com cada uma das varias afirmações relacionadas aos objetos de estímulo. Antes de ser aplicado o questionário definitivo foi realizado um pré-teste.

O universo e/ou população desta pesquisa foi composto pelo conjunto de todos os servidores técnico-administrativos do IFRN Campus Natal-Central, que totalizam 209 (duzentos e nove), funcionários, como foi verificado no Sistema Unificado de Administração Pública - SUAP, que é um programa desenvolvido pela equipe de desenvolvimento de sistemas da DIGTI do IFRN.

Foi aplicado o questionário a um grupo de 136 (cento e trinta e seis) funcionários, levando em consideração os cálculos dos determinantes para o tamanho de uma amostra finita dentro do 
critério de 5\% de margem de erro, desenvolvida por Krejcie e Morgan (1970), no qual para um universo de 210 indivíduos uma amostra probabilística deve contemplar 136 questionários.

Os dados coletados pelo presente trabalho foram analisados em 3 etapas: primeiramente a análise do perfil dos sujeitos questionados; depois, a análise dos fatores motivacionais referentes aos objetivos da pesquisa e por fim a análise de cluster realizados através do software Statistic 7.0.

\section{ANÁLISE DOS RESULTADOS}

A coleta dos dados aconteceu no período de 15 de setembro a 20 de novembro de 2013, com uma população de 136 servidores técnicos administrativos lotados no IFRN campus Natal Central. Os dados coletados foram analisados em 3 etapas: primeiro traçou-se o perfil dos entrevistados, na sequência foram feitas as análises das informações referentes aos fatores de satisfação e motivação que interferem no desempenho dos servidores. E posteriormente desenvolve-se a analise de Cluster para separar os pesquisados em dois grupos mais homogêneos, atendendo aos objetivos específicos desta pesquisa.

Foram aplicados 136 questionários aos técnicos administrativo lotados no IFRN, Campus Natal Central uma vez que foi tentado homogeneizar todo o espaço amostral dentro do critério de 5\% desenvolvida por Krejcie e Morgan (1970).

\subsection{DESCRIÇÕES DO PERFIL DOS SERVIDORES}

Com relação aos aspectos referentes ao perfil dos entrevistados, o gênero dos entrevistados foi de $35 \%$ do sexo feminino e $65 \%$ do sexo masculino. Quanto ao estado civil, $65,4 \%$ são casados, $20,6 \%$ solteiros, $8,1 \%$ separados, $4,4 \%$ divorciados e $1,5 \%$ respondeu outras formas de união.

Sobre a faixa etária dos respondentes, encontrou-se $2,2 \%$ possuem idade entre 24 anos ou menos; 7,4\% tem idade de 25 a 30 anos; $17,8 \%$ tem idade entre 31 a 35 anos; $11,8 \%$ possuem idade entre 36 a 40 anos e $61 \%$ estão acima de 41 anos. Isso demonstra que a maior parte dos servidores estão com idade de 41 anos ou acima, portanto, a força de trabalho apresenta boa experiência de vida, o que pode contribuir de forma positiva na formação dos alunos.

Com relação à escolaridade, os dados se mostraram da seguinte forma: $2,9 \%$ dos respondentes possuem o ensino fundamental incompleto; $2,2 \%$ o ensino fundamental completo; $2,2 \%$ o ensino médio incompleto $8,8 \%$ ensino médio completo; $18,4 \%$ superior incompleto; $16.9 \%$ graduação completa; $36 \%$ com pós-graduação completa; $11 \%$ com mestrado e 1,5\% com doutorado. Com esses números, percebe-se que a maioria dos servidores possui pós-graduação, que se pelo fato que os servidores estão preocupando-se em cada vez mais correr em busca de qualificação pelo fato que de com isso ter mais oportunidades dentro da instituição, assim como estímulo salarial.

Quanto ao tempo de serviço no IFRN, 2,9\% tem até 11 meses de serviço na instituição; 27,2\% tem ente 1 a 5 anos; 7,54\% entre 6 e 10; 3,7\% tem de 11 a 15 anos; 17,6\% tem 16 a 20 anos e $41,2 \%$ estão com mais de 21 anos de serviço. Verifica-se com esse resultado que $41 \%$ dos servidores já trabalham na instituição há mais de 20 anos, reforçando que os pesquisados possuem amplo conhecimento da instituição. 


\subsection{MOTIVAÇÃO E SATISFAÇÃO DOS SERVIDORES}

Considerando-se que a motivação e a satisfação com o trabalho promovem bem-estar e melhoria nas relações pessoais e na prestação do serviço oferecido, a Figura 1 apresenta o nível de motivação dos servidores do IFRN Campus Natal Central.

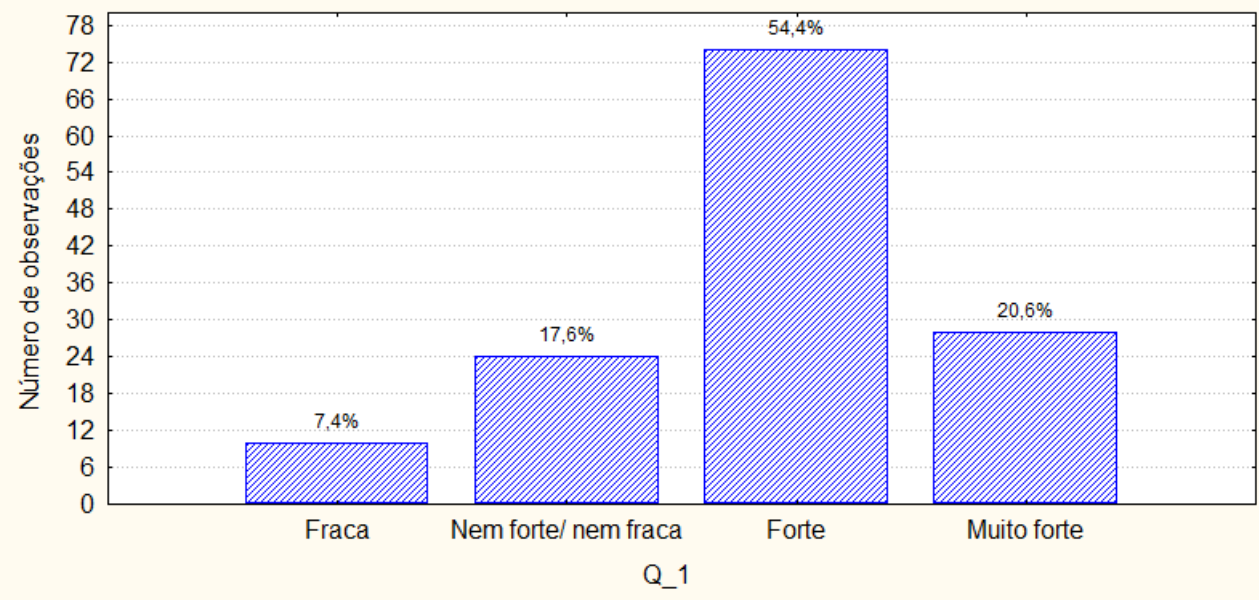

Figura 1 - Nível de Motivação para com o trabalho no IFRN

Fonte: Dados da pesquisa

A Figura 1 apresenta que entre os 136 servidores pesquisados, 54,4\% sentem uma forte motivação por trabalharem no IFRN Campus Natal Central e $20,6 \%$ tem uma motivação muito forte, $7,4 \%$ tem uma motivação muito fraca e $17,6 \%$ sentem-se indiferente. Neste aspecto, com base em que $75 \%$ das pessoas se sentem motivadas ou fortemente motivadas, evidencia que a maioria deve gostar do trabalho que desenvolve. Esse mesmo resultado se confirma no nível de satisfação com o trabalho que desenvolve, conforme Figura 2.

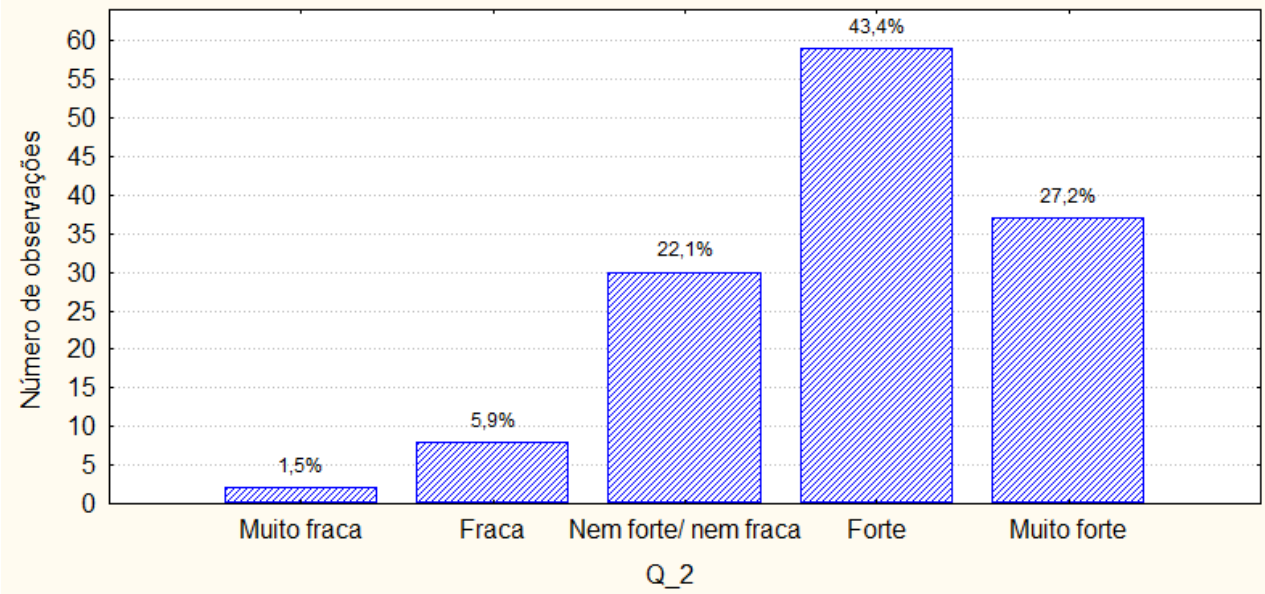

Figura 2 - Nível de satisfação quanto ao trabalho que executa no IFRN Fonte: Dados da pesquisa

A pesquisa apontou que as maiorias dos servidores do IFRN Campus Natal Central estão satisfeito com seu trabalho. Foram $43,4 \%$ servidores que tiveram uma forte satisfação e $27,2 \%$ tiveram uma satisfação muito forte com o trabalho que executam o que represente basicamente $70 \%$ da força de trabalho. Sendo que, $22,1 \%$ responderam que são indiferentes e $5,9 \%$ tem uma motivação fraca e $1,5 \%$ muito fraca. Esses resultados demostram que a maioria dos servidores 
devem trabalhar com o que gostam, promovendo uma forte relação e sentindo-se satisfeitos como o seu trabalho.

No que se refere aos desafios que encontram com o seu trabalho no IFRN Campus Natal Central, é possível identificar que muitos servidores sentem que possuem um trabalho desafiador, $51,5 \%$ acreditam que seu trabalho tem um desafio forte, $24,3 \%$ responderam que tem um desafio muito forte. Ainda assim, 17,8\% é indiferente e 6,6\% tem uma percepção fraca em relação aos desafios de seu trabalho.

Quanto à importância de suas atividades para a missão do IFRN que é a educação, os funcionários sentem que tem uma importância forte. Porque entre os respondentes, $40,7 \%$ dos servidores técnico administrativos concordam que suas atividades são importantes para a missão do IFRN, enquanto que apenas 5,2\% tem uma percepção muito forte em relação à importância de suas atividades para essa missão. Um percentual bem representativo, na faixa de 33,3\% não tem muita percepção sobre esse motivador, já que marcaram que seu trabalho não é nem forte/nem fraco para contribuir com a missão institucional. Já $18,5 \%$ sente que seu trabalho para essa missão é fraco e 2,2\% é muito fraco, o que demonstra que a maioria dos servidores não sente que seu trabalho tem uma importância forte e muito forte para com a missão do IFRN Campus Natal Central. Esse aspecto requer mais investigações possui grande influência na prestação dos serviços públicos ofertados.

No decorrer do instrumento de pesquisa, os respondentes foram questionados sobre o nível de reconhecimento do trabalho, 35,3\% dos servidores percebem que seu trabalho tem um reconhecimento forte, já $8,1 \%$ responderam o nível de reconhecimento é muito forte. Dessa forma, $43,4 \%$ consideram que o trabalho que desenvolvem é reconhecido. No entanto, a maioria não apresentou essa percepção, porque $34,6 \%$ marcaram não é nem e forte nem fraco o reconhecimento do seu trabalho e $22 \%$ sentem como fraco ou muito fraco o reconhecimento do trabalho, o que pode ocasionar desmotivação para com o trabalho.

Os dados levantados através da aplicação do questionário no IFRN Campus Natal Central sobre a questão da disseminação da comunicação interna, apresentou que 43,4\% tem uma percepção forte em relação à comunicação interna do IFRN Campus Natal central e apenas 5,9\% tem essa percepção como muito forte. Já $30,1 \%$ dos respondentes alegam indiferentes quanto a essa questão já que responderam na escala a alternativa "nem forte nem fraco", e 15,4\% responderam que tem essa percepção fraca e 5,1\% muito fraca.

Outro aspecto pertinente foi sobre o nível de preocupação que o IFRN possui em manter o funcionário informado e satisfeito com a informação. Nesse quesito, os funcionários possuem uma forte percepção em relação à preocupação que o IFRN tem em relação a manter os funcionários informados porque $46,3 \%$ apresenta forte concordância sobre a qualidade da informação e 12,5\% tem uma percepção muito forte. No entanto 35,5\% responderam que são indiferentes e 5,9\% apresenta uma fraca concordância com a questão.

Para um melhor entendimento dos aspectos que geram motivação e que se refletem como principais fatores de satisfação para os servidores do IFRN Campus Natal Central, a pesquisa evidenciou que os funcionários estão satisfeitos (51,5\%) para com o ambiente de trabalho, 48,5\% estão satisfeitos com o trabalho em si. Dentre os pesquisados, $47,1 \%$ estão satisfeitos com a forma como é desenvolvida a avaliação de desempenho e apenas $36 \%$ encontram-se satisfeitos com a remuneração. Evidenciou-se também que os respondentes, em sua maioria, se encontram 
satisfeitos com as horas trabalhadas, com a facilidade de acesso os setores, com a comunicação interna, com os equipamentos e mobiliários e com a limpeza do ambiente de trabalho.

Nesse sentido, levando-se em consideração que um trabalhador só tem como "vender" um serviço se estiver de forma geral, satisfeito. Dessa forma, podem ser considerados positivos os resultados sobre a percepção de satisfação com aspectos relacionados com o trabalho e ao ambiente de trabalho. Os servidores do IFRN Campus Natal Central, apesar de não serem unânimes, gostam da instituição o que geram uma propensão a desempenharem de forma melhor o seu trabalho e assim desenvolver um melhor serviço ao cidadão usuário.

\subsection{ANÁLISE DE CLUSTER}

As questões aplicadas a partir do questionário foram analisadas através de testes estatísticos de análise de cluster. Para esse estudo a variável Q13E (satisfação com as horas trabalhadas), não apresentou significância estatística e foi retirada. Isso mostra que os outros apresentaram p-valor inferior a 0,05.

Realizado o teste na primeira rodada foi retirado o Q13E para ser realizada uma segunda rodada, na qual as demais variáveis apresentaram variância dentro de um padrão esperado. Na sequência, essas variáveis foram utilizadas para analisar de Cluster.

As medias e os desvios padrão dos dois clusters podem ser visualizados no quadro 1.

Quadro 1 - Média e Desvio padrão dos Clusters 1 e 2

\begin{tabular}{|c|c|c|c|c|c|}
\hline \multicolumn{3}{|c|}{$\begin{array}{l}\text { Cluster } 1 \text { - } 55 \text { casos } \\
\text { Servidor Menos Satisfeito }\end{array}$} & \multicolumn{3}{|c|}{$\begin{array}{c}\text { Cluster } 2 \text { - } 81 \text { casos } \\
\text { Servidor mais Satisfeito }\end{array}$} \\
\hline Variável & Média & Desvio Padrão & Variável & Média & Desvio Padrão \\
\hline Q_1 & 3,345455 & 0,750757 & Q_1 & 4,246913 & 0,642862 \\
\hline Q_2 & 3,254545 & 0,886487 & Q_2 & 4,320988 & 0,667592 \\
\hline Q_3 & 3,418182 & 0,896308 & Q_3 & 4,259259 & 0,628048 \\
\hline Q_4 & 3,436363 & 0,833636 & Q_4 & 4,271605 & 0,632699 \\
\hline Q_5 & 2,563637 & 0,764093 & Q_5 & 3,768907 & 0,614314 \\
\hline Q_6 & 2,909091 & 0,822659 & Q_6 & 3,888888 & 0,632456 \\
\hline Q_7 & 2,563636 & 0,713978 & Q_7 & 3,753087 & 0,766989 \\
\hline Q_8 & 3,200001 & 1,025598 & Q_8 & 3,716049 & 0,728604 \\
\hline Q_9 & 4,054546 & 0,730758 & Q_9 & 4,296298 & 0,621378 \\
\hline Q_10 & 2,672728 & 1,00101 & Q_10 & 3,716049 & 0,693444 \\
\hline Q_11 & 3,109091 & 0,895932 & Q_11 & 4,08642 & 0,616391 \\
\hline Q_12 & 3,181818 & 0,611341 & Q_12 & 3,975309 & 0,70667 \\
\hline Q_13_A & 2,800000 & 1,078408 & Q_13_A & 3,358025 & 0,841258 \\
\hline Q_13_B & 3,181818 & 0,795611 & Q_13_B & 4,222222 & 0,612373 \\
\hline Q_13_C & 3,509091 & 0,836056 & Q_13_C & 4,333333 & 0,632456 \\
\hline Q_13_D & 3,072727 & 0,920035 & Q_13_D & 3,641976 & 0,795435 \\
\hline Q_13_F & 3,363637 & 0,778499 & Q_13_F & 3,802469 & 0,812708 \\
\hline Q_13_G & 2,581818 & 0,786245 & Q_13_G & 3,716049 & 0,745563 \\
\hline Q_13_H & 2,490909 & 1,051854 & Q_13_H & 3,432099 & 0,986639 \\
\hline Q_13_I & 3,309091 & 1,069315 & Q_13_I & 3,962963 & 0,843274 \\
\hline Q_13_J & 3,654545 & 0,886487 & Q_13_J & 3,975308 & 0,865669 \\
\hline
\end{tabular}

Fonte: Dados da pesquisa

O Cluster 1 foi formado por 55 casos e foi nomeado para a pesquisa como os servidores menos satisfeitos, enquanto que o cluster 2 foi formando por 81 casos e nomeado como servidores mais satisfeitos. 
Os dados da Tabela 1 também podem ser visualizados na Figura 3.

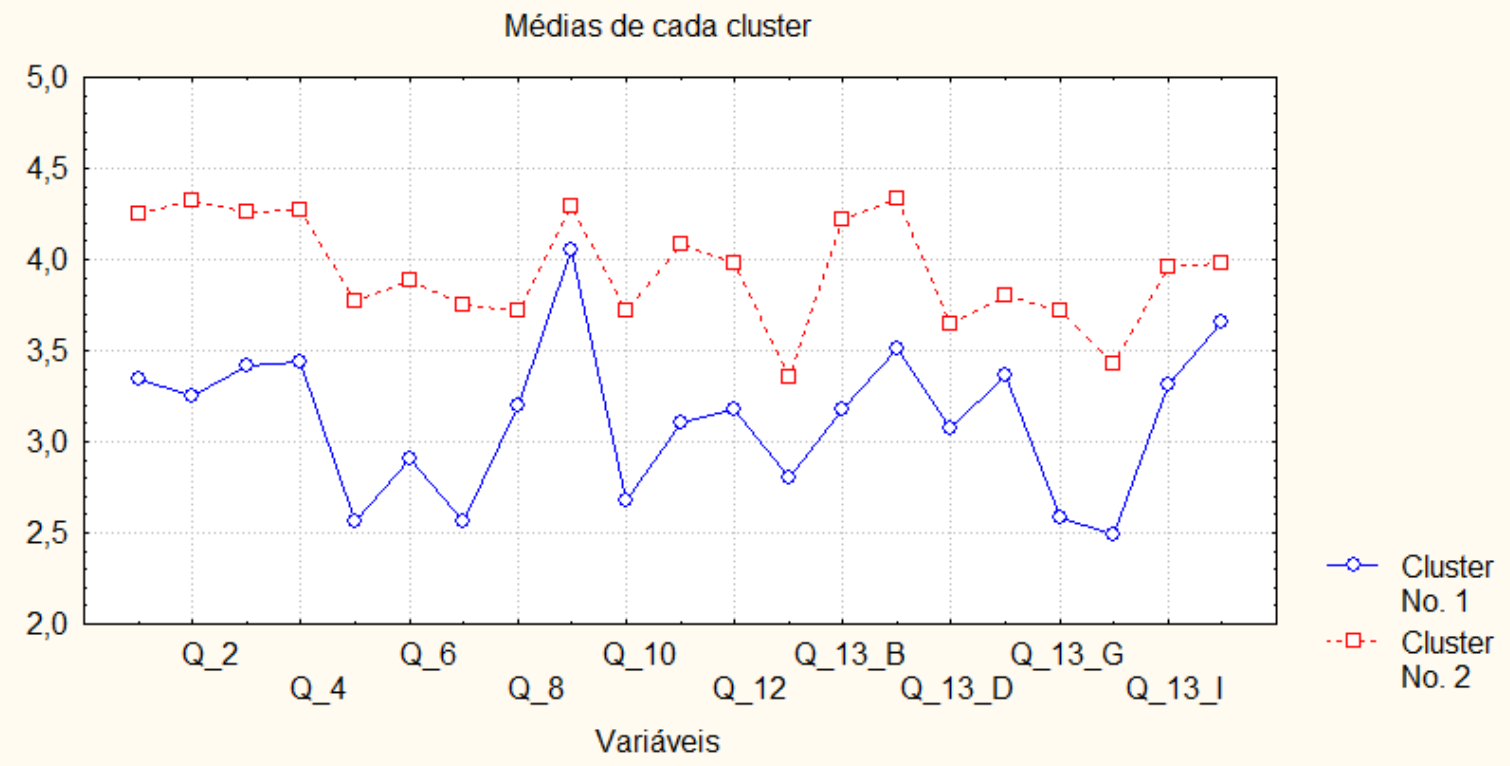

Figura 3 - Gráfico dos Clusters 1 e 2

Fonte: Dados da pesquisa

Analisando a figura 3 existe um grupo de servidores que apresentam uma forte satisfação em relação ao seu trabalho como poder ser observado no cluster 2 , que apresenta alguns pontos que se sobressaem nas escalas em relação ao cluster 1 . O que permite analisar que alguns servidores tem uma tendência a estar mais satisfeito em trabalhar no setor atual, que a qualidade das informações prestada pela instituição é suficiente, que o instrumento de informação e o tempo com que essas informações chegam até eles são satisfatórios e que são reconhecidos com os seus trabalhos prestados. Assim como, recebem informações claras em relação as suas atividades e se sente satisfeitos em relação ao trabalho, a comunicação interna e consideram que os cursos de capacitação são satisfatórios. Esse agrupamento (cluster 2 ) tem uma percepção mais positiva em relação a esses aspectos do que os indivíduos agrupados no cluster 1, que tendem a uma insatisfação em relação aos mesmos aspectos analisados.

Essa divisão clara entre os dois agrupamentos, no decorrer da pesquisa, levantou a suposição de que os servidores menos motivados seriam os profissionais com mais tempo na instituição. Diante dessa suspeita, analisando-se os dados em um cluster que priorizou a variável "tempo de instituição", verificou-se que os funcionários com mais tempo na instituição tiveram uma percepção menos positiva em relação à satisfação, sentindo-se menos motivados com o seu trabalho. Dessa forma, é necessário desenvolver estratégias para os servidores com mais tempo de instituição de forma que torne a devolvê-los o prazer em trabalhar. Estimulando o sentido do trabalho para a geração de satisfação e consequente motivação.

\section{CONSIDERAÇÕES FINAIS}

A motivação provém do interior das pessoas e portanto, nenhum indivíduo é capaz de motivar o outro. O que é possível é tentar de alguma forma buscar despertar a motivação dos colaboradores. Esse panorama é ainda mais complexo nas organizações públicas, nas quais pode ser difícil influenciar e tentar manter motivados seus colaboradores, tendo em vista que cada 
pessoa tem interesses, desejos, habilidades e aptidões para realizar suas atividades pessoais e profissionais de forma diferente.

Na busca de identificar os aspectos da satisfação e motivação dos funcionários técnico administrativos do IFRN Campus Natal Central, esta pesquisa verificou que existe um grupo de servidores que é mais satisfeito do que outro, com 81 casos.

De forma geral, os técnicos administrativos estão satisfeitos com o ambiente de trabalho, com as informações recebidas, sentem reconhecimento no trabalho que desenvolvem, dentre outros demonstrando forte motivação para com o trabalho que desenvolvem.

Apesar de positivo o resultado existe um agrupamento que tende a uma visão menos positiva em todos os aspectos analisados e que se suspeitou que pudesse existir uma relação entre o tempo de serviço e o nível de satisfação. Portanto, desenvolveu-se uma análise de cluster discriminando a variável tempo de serviço na instituição e o resultado demostrou que os servidores mais motivados são servidores com menos tempo de serviço.

Esse achado é muito representativo para o desenvolvimento de estratégias que focalizem em como aumentar o nível de motivação e satisfação para os profissionais com maior tempo de serviço, promovendo e retornando o sentido do trabalho que desenvolvem.

A elaboração desta pesquisa foi significativa para a instituição pesquisada, porque permite compreender que mesmo os servidores sendo concursados e terem uma estabilidade garantida, existem outros fatores que necessitam de maior atenção e que se bem trabalhados podem elevar o nível de motivação e satisfação das pessoas no ambiente de trabalho, tornando-se possível que pontos negativos sejam minimizados e pontos positivos sejam fortalecidos, incrementando melhorias e fortalecendo o desenvolvimento de inovações capazes de favorecer tanto ao funcionário quanto à organização.

Assim, sugerem-se novas pesquisas relacionadas com o tema, pois é vasto e complexo. Recomenda-se também o desenvolvimento de estudos futuros que possam ajudar a desenvolver ações concretas que visem melhorar e corrigir alguns fatores verificados através deste estudo, e que podem acarretar desmotivação e insatisfação dos servidores públicos federais.

\section{REFERÊNCIAS}

1. BRASIL. Constituição (1988). Constituição República Federativa do Brasil. Brasília: Senado Federal; Centro Gráfico, 1988. 292 p.

2. BRUM, Analisa de Medeiros. Endomarketing de $\mathbf{A}$ a Z: como alinhar o pensamento das pessoas à estratégia da empresa. São Paulo, Integrare Editora, 2010.

3. CARVALHO, Antonio Vieira de; NASCIMENTO, Luiz Paulo do. Administração de Recursos Humanos. Vol I. São Paulo: Pioneira, 2004.

4. COBRA, Marcos. Serviços: como construir valor para o cliente. São Paulo: Marcos Cobra, 2004.

5. _ Administração de Marketing no Brasil. 3. ed. Rio de Janeiro: Elservier, 2009.

6. CORRÊA, Tupâ G.; FREITAS, Sidinéia G. (Orgs.) Comunicação, marketing, cultura: sentidos da administração do trabalho e do consumo. São Paulo: ECA/USP, 1999.

7. GIL, Antonio Carlos. Como Elaborar projetos de pesquisa. 5. ed. São Paulo: Atlas 2010. 
8. KLIKSBERG, Bernardo. A gerência no final do século XX. Revista de Administração Pública. v. 27, n.2, p. 183-201, abr./jun., 1993.

9. KREJCIE, Robert V.; MORGAN, Daryle W. Determining sample size for research activities. Educational and Psychological Measurement, n. 30, p. 607-610, 1970.

10. LOVELOCK, Christopher; WRIGHT, Lauren. Serviços: marketing e gestão. São Paulo: Saraiva, 2001.

11. MALHOTRA, Naresk K. Pesquisa de Marketing: Uma orientação aplicada. 4. ed. Porto Alegre: Bookman, 2006.

12. MENDES, Regina Stela Almeida Dias. Endomarketing como ferramenta de comunicação com - público interno. Universidade Federal de Juiz de Fora, 2004. Disponível em: <http://www.endomarketing.com/diversos/artigo_publico_interno.pdf> Acesso em: 20 jun. 2013.

13. ROBBINS, Stephen P. Comportamento Organizacional. 11. ed. São Paulo: Prentice Hall, 2009.

14. SOUZA, Paulo Nathanael Pereira de. Educação e Desenvolvimento no Brasil. São Paulo: Integrare Editora, 2008.

15. WEISINGER, Hendrie. Inteligência Emocional no Trabalho, como aplicar os conceitos revolucionários da I.E. nas suas relações profissionais reduzido o estresse aumentando sua satisfação, eficiência e competitividade. Rio de Janeiro: Objetiva, 2001. 